\title{
La otra cara de la talidomida
}

\author{
René A. Rodríguez
}

\begin{abstract}
"The further we look into the past, the further we look into the future." Sir Winston Churchill
\end{abstract}

La compañía suiza Ciba sintetizó, en 1953, una droga derivada del ácido glutámico a la que denominó talidomida. No le encontró aplicación terapéutica en animales, por lo cual decidió archivar este proyecto (1-3).

Hacia 1956, la compañía alemana Grünenthal la sintetizó de nuevo, lanzándola al mercado como útil para el tratamiento de la epilepsia. No funcionó como tal, pero, se encontró que producía sueño. Muy pronto se volvió el sedante más popular en Alemania por ser una droga de venta libre y de bajo costo.

Posteriormente, la talidomida fue añadida a medicamentos usados para el resfriado común, el asma, la migraña y las neuralgias. Por su uso tan difundido, se evidenció su utilidad como antiemético durante el embarazo. La droga alcanzó gran demanda y se distribuyó en varios países del mundo, como Inglaterra, Portugal, Estados Unidos, Canadá y Brasil, entre otros. En 1961, se descubrió que la droga producía neuritis, razón por la cual pasó a ser usada únicamente por prescripción médica $(1,2)$.

A finales de los 50 y principios de los 60 , la comunidad médica europea comenzó a notar con preocupación un aumento en la incidencia de malformaciones congénitas $(1,4)$. A raíz de esto, se emprendieron numerosos estudios, todos retrospectivos, tratando de establecer su causa (1).

En 1961, Wiedemann informó sobre 33 recién nacidos con malformaciones congénitas en donde la alteración del tejido mesenquimatoso constituía

Médico y cirujano, en servicio social obligatorio, Laboratorio de Patología, INS. un nuevo síndrome. El hallazgo más característico era el compromiso de los huesos largos de las extremidades; se tornaban cortos o estaban ausentes. El compromiso de los miembros inferiores era menos severo que el de los miembros superiores. La mano, cuando la afección de los huesos del miembro superior era mayor, nacía muy cercana del hombro, por lo cual las extremidades semejaban las de las focas. Por eso, la malformación recibió el nombre de focomelia (del griego phoke, foca, y melia, extremidades). Estos niños además presentaban poli o sindactilias de los artejos, agenesia del oido externo, malrotaciones y atresias intestinales, asplenia, útero bicorne, parálisis facial unilateral y malformaciones cardiacas que no seguían un patrón específico. Un hallazgo adicional característico era la presencia de un hemangioma centrofacial. Los niños no presentaban alteraciones mentales (1).

El médico alemán Widulind Lenz encontró que más del $50 \%$ de las madres de los niños afectados había recibido talidomida durante el embarazo. Con este hallazgo, alertó a la compañía Grünenthal y sugirió retirar la droga del mercado. El 20 de noviembre de 1961 en la reunión pediátrica de Dusseldorf, Lenz notificó que un medicamento era el responsable del nuevo síndrome y seis días más tarde la compañía retiró del mercado la talidomida $(1,2,5,6)$. Por la misma fecha, en Australia, W.G. McBride llegó a la misma conclusión $(2,4,6)$.

A la talidomida se le acusa de ser la responsable de las malformaciones congénitas de cerca de 12.000 niños en Europa, 10.000 de las cuales ocurrieron en la entonces República Federal Alemana (7).

Cuatro años más tarde, se supo nuevamente de la droga. En el Hospital Rothchild Hadassah en Israel, el dermatólogo J. Sheskin trató seis 
enfermos con eritema nodoso leproso, pensando que la droga los sedaría, disminuyéndoles el dolor y el malestar. Quedó sorprendido al observar una mejoría dramática de las lesiones y del estado general de estos pacientes. A los dos días de su uso, todos presentaron la remisión de su cuadro. Gracias a este hallazgo, que constituye un típico ejemplo de serendipity, hoy en día se cuenta con una droga "milagrosa" y de primera elección para el tratamiento del eritema nodoso leproso (8-11), que es la indicación primordial de la talidomida.

Posteriormente, su uso se extendió a varias entidades, dermatológicas principalmente, con resultados prometedores (tabla 1).

Fabio Londoño, en el Centro Dermatológico Federico Lleras Acosta de Bogotá, fue el pionero en el uso de la talidomida para el tratamiento del prurigo actínico, con resultados excelentes (14).

La talidomida es una droga poco soluble en agua y en lípidos. Se presenta en tabletas de $100 \mathrm{mg}$. La dosis promedio está entre 100-400 mg/d, según la entidad y la respuesta del paciente $(1,3)$.

Es un potente inmunosupresor y antiinflamatorio. Se le han encontrado varios efectos que pueden explicar, en parte, su mecanismo de acción:

- Inhibe la quimiotaxis de los PMN (27). Es posible que esta acción se relacione con su utilidad en el manejo de algunas dermatosis neutrofílicas nodulares y difusas, tales como el pioderma gangrenoso, las aftas y el eritema nodoso leproso. El dermatólogo J.G. Chalela trató con talidomida a un paciente con yododerma, entidad también caracterizada por su infiltrado dérmico rico en neutrófilos, y obtuvo una mejoría rápida y notoria (comunicación personal).

- Inhibe la síntesis de novo de IgM(3). Es posible que este mecanismo también sea responsable de su efecto dramático en el eritema nodoso leproso.

- Inhibe la producción del factor de necrosis tumoral alfa (TNF- $\alpha$ ) por los monocitos (28).

- Interfiere en la expresión de los receptores B2 de las integrinas presentes en las membranas celulares leucocitarias (LFA-1, MAC-1 y p150,95) (29-31).
Tabla 1. Entidades en las cuales la talidomida ha demostrado ser útil (referencias).

$\begin{array}{lr}\text { Prurigo actínico } & (3,12-14) \\ \text { Lupus eritematoso discoide } & (3,12,15,16) \\ \text { Prurigo nodular } & (3,12,15,17) \\ \text { Aftas orales recidivantes } & (3,12,18,19) \\ \text { Pioderma gangrenoso } & (3,20) \\ \text { Síndrome de Behçet } & (20-22) \\ \text { Eritema multiforme } & (3,15,23) \\ \text { Enfermedad de injerto vs. huésped } & (8,24,25) \\ \text { Artritis reumatoidea } & (8,26)\end{array}$

- Disminuye la relación de linfocitos T ayudadores/linfocitos T supresores (LTH/LTS) (15, 24).

Se han informado numerosos efectos indeseables. El más importante es la teratogénesis la cual se presenta si se ingiere la droga entre la tercera y la sexta semana del embarazo; pero, quizás el tiempo crítico de susceptibilidad del feto a la droga tenga un rango más estrecho, dentro de estas semanas de la embriogénesis (1). Una sola dosis de $100 \mathrm{mg}$ de talidomida es suficiente para producir las malformaciones (1).

Hay varias hipótesis que tratan de explicar el mecanismo de la teratogenesis:

1. Para que haya un desarrollo embriológico adecuado se necesita que las comunicaciones célula-célula y célula-matriz se efectúen adecuadamente; éstas son responsabilidad de las integrinas y de las moléculas de adhesión (32). Se piensa que la talidomida altera estas comunicaciones, interfiriendo con la síntesis de las integrinas o modificando las moléculas de adhesión (29).

2. Experimentos con animales han demostrado que los ratones no son susceptibles a este efecto. Por otra parte, los conejos y los primates, incluido el hombre, sí lo son. El hígado de estos animales susceptibles sintetiza un metabolito tóxico (óxido-areno) que, al parecer, es el responsable de las malformaciones (33).

La polineuropatía es otra complicación descrita desde el comienzo del uso de la talidomida (34). Se caracteriza por parestesias, debilidad muscular, alteraciones neurovegetativas, enrojecimiento de las palmas, pérdida de la sensibilidad 
superficial y profunda y un umbral aumentado al prurito $(3,34)$. A este último efecto se le atribuye su acción benéfica en el prurigo nodular. Debido a la rareza del uso de la droga, no se ha podido establecer si la neuropatía es dosis-dependiente o si se deba a su uso crónico. Tampoco se conoce con exactitud si ésta revierte con la suspensión del medicamento (35). Cuando se ha usado en el manejo de la reacción tipo 2 en la lepra, no se aumenta el efecto neurítico ya existente.

Algunos pacientes con SIDA que han requerido la droga por padecer de aftas orales recidivantes, desarrollan un tipo de reacción de hipersensibilidad pocas horas después de ingerirla. Se caracteriza por una erupción macular eritematosa y generalizada, acompañada de fiebre, taquicardia e hipotensión (37).

Otros efectos indeseables son: sueño, vértigo, cefalea, estreñimiento, náuseas, xerodermia, xerostomía, erupciones, aumento de peso, edema e irritabilidad $(3,15,24,35,36)$.

La talidomida no es de venta corriente en nuestro país ni en el mundo. El Ministerio de Salud Pública la adquiere mediante contrato especial con el Laboratorio Grünenthal, para el manejo de la reacción leprótica tipo 20 eritema nodoso leproso. La distribuye gratuitamente a los servicios de salud, según los casos de eritema nodoso leproso, reacción que se presenta en el $50 \%$ de los pacientes con lepra lepromatosa (38). La droga es difícil de conseguir para otras indicaciones.

Las nuevas aplicaciones de la talidomida son múltiples y muchas realmente útiles. Es deseable que esas acciones se sometan al riguroso análisis de ensayos clínicos controlados para que dejen de tener un sentido anecdótico. Es muy posible que esta droga, que en el pasado afectó a un gran número de niños y a sus familias, en el futuro brinde una mejor calidad de vida a muchas personas con enfermedades incapacitantes en las que se está demostrando su efectividad.

Los médicos, en especial los dermatólogos, manejan a veces otros medicamentos más tóxicos o peligrosos que la talidomida. La única contraindicación absoluta es su uso en mujeres en edad fértil, en las que no se pueda garantizar la anticoncepción segura. Por consiguiente, conocidas sus condiciones terapéuticas múltiples, las autoridades de salud y el gremio de dermatólogos deberían hacer esfuerzos conjuntos y coordinados para que la droga esté disponible, al menos, en las instituciones universitarias médicas colombianas.

\section{Referencias}

1. Taussig HB. A study of the German outbreak of phocomelia. JAMA 1962;180:1106-14.

2. Randall T. Thalidomide has a 37-year history. JAMA 1990;263:1474.

3. Grosshans E, Illy G. Thalidomide therapy for inflammatory dermatoses. Int J Dermatol 1984;23:598.

4. McBride W.G. Thalidomide and congenital abnormalities. Lancet 1961;2:1358.

5. Lenz $\mathbf{W}$. Thalidomide and congenital abnormalities. Lancet 1962;1:45.

6. Lenz $\mathbf{W}$. A personal perspective on the thalidomide tragedy. Teratology 1992;46:416.

7. SkolnickA. Key witness against morning sickness. Drug faces scientific fraud charges. JAMA 1990;263:1468.

8. Randall T. Thalidomide is back in the news, but in more favorable circumstances. JAMA 1990;263:1467.

9. Jadhav VH, Pakti AH, Mehta JM. Thalidomide in type-2 lepra reaction: a clinical experience. Indian J Lepr 1990;62:316.

10. Sheskin J, Sagher F. World survey on the use of thalidomide in leprosy reaction. Med Cutan Iber LatAm 1975;3:81.

11. Jakeman P, Smith WC. Thalidomide in leprosy reaction. Lancet 1994;343:132.

12. Carmichael AJ, KnightA. Thalidomide: a restricted role. Lancet 1992;339:1362.

13. Bernal JE, Durán MM, Londoño F, Umaña A. Cellular immune effects of thalidomide in actinic prurigo. Int $\mathrm{J}$ Dermatol 1992;31:599.

14. Londoño F. Thalidomide in the treatment of actinic prurigo. int J Dermatol 1973;12:326.

15. Naaf B, Faber WR. Thalidomide therapy. An open trial. Int J Dermatol 1985;24:131.

16. Barba J, Franco F. Lupus eritematoso discoide y talidomida. Dermatología Rev Mex 1975;19:131.

17. Winkelmann RK, Connolly SM, Doyle JA, et al. Thalidomide treatment of prurigo nodularis. Acta Derm Venereol 1984;64:412.

18. Radeff B, Kuffer R, Samson J. Recurrent aphtous ulcer in patients infected with human immunodeficiency virus: 
successful treatment with thalidomide. J Amer Acad Dermatol 1990;23:523.

19. Revuz J, Guillaume JC, Janier M, et al. Crossover study of thalidomide vs. placebo in severe recurrent aphtous stomatitis. Arch Dermatol 1990;126:923.

20. Rustin MH, Gilkes JJ, Robinson TW. Pyoderma gangrenosum associated with Behcet's disease: treatment with thalidomide. J Am Acad Dermatol 1990;23:941.

21. Larsson $\mathbf{H}$. Treatment of severe colitis in Behcet's syndrome with thalidomide (CG-217). J intern Med 1990;228:405.

22. Jorizzo JL, Schmalstieg FC, Solomon AR, et al. Thalidomide effects in Behcet's syndrome and pustular vasculitis. Arch Intern Med 1986;146:878.

23. Moisson YF, Jainer M, Civatte $J$. Thalidomide for recurrent erythema multiforme. Br J Dermatol 1992;126:92.

24. Randall T. Research focuses on immunosuppressive effect, unknown teratogenic mechanism of thalidomide. JAMA 1990;263:1473.

25. Vogelsang GB, Farmer ER, Hess AD, ef al. Thalidomide for the treatment of chronic graft versus host disease. $\mathrm{N}$ Eng J Med 1992;326:1055.

26. Gutiérrez $\mathbf{O}$, Starusta $P$, Gutiérrez $O$. Treatment of refractory rheumatoid arthritis. The thalidomide experience. J Rheumatol 1989;16:158.

27. Faure M, Gaucherand M. Inhibition of PMN leucocytes chemotaxis by thalidomide. Arch Dermatol Res 1980;269:275.
28. Sampaio EP, Sarno EN, Galilly R, et al. Thalidomide selectively inhibits tumor necrosis factor alfa production by stimulated human monocytes. J Exp Med 1991;173:699.

29. Neubert R, Nogueira AC, Neubert D. Thalidomide and the immune system. 2. Changes in the receptors on blood cells of a healthy volunteer. Life Sciences 1992;51:2107.

30. Springer T. Adhesion receptors of the immune system. Nature 1990;346:425.

31. Hemler M. Adhesive protein receptors on hematopoietic cells. Immunol Today 1988;9:109.

32. Hynes R. Integrins: a family of cell surface receptors. Cell 1987; $48: 549$.

33. Gordon G, Spilberg S, Blake D, Balasubramanian V. Thalidomide teratogenesis: evidence for a toxic arene oxide metabolite. Proc Natl Acad Sci 1981;78:2545.

34. Kelsey F. Thalidomide neuropathy. JAMA 1962;179:242.

35. Crawford CL. Thalidomide neuropathy. N Eng J Med 1992;327:735.

36. Hooper M. Use of thalidomide in leprosy. BMJ 1991; 303:1404.

37. Anderson $\mathrm{J}$, Waters MF. Thalidomide hypersensitivity in AIDS. Lancet 1991;337:436.

38. Rodríguez G. Estados reaccionales. En: Lepra. Rodríguez G, Orozco LC, Sarmiento C, editores. Bogotá: Instituto Nacional de Salud, 1995 (en prensa). 